\title{
Analysis of the Compressibility Effect of Overburden in a Deep Shield Tunnel Based on the Effect of the Pressure Arch
}

\author{
Ping Lei $\mathbb{D}^{1},{ }^{1}$ Xin Han $\left(\mathbb{D},{ }^{1}\right.$ Fei Ye $\mathbb{D}^{1},{ }^{1}$ Xing Liang, ${ }^{1}$ Biao He, ${ }^{1}$ and Zhi-jun Duan ${ }^{2}$ \\ ${ }^{1}$ School of Highway, Chang'an University, 710064 Xi'an, Shanxi, China \\ ${ }^{2}$ China Railways Siyuan Survey and Design Group Co., Ltd., 430063 Wuhan, Hubei, China \\ Correspondence should be addressed to Xin Han; hanxin@chd.edu.cn
}

Received 22 December 2018; Revised 10 May 2019; Accepted 23 May 2019; Published 13 June 2019

Academic Editor: Salvatore Grasso

Copyright ( 12019 Ping Lei et al. This is an open access article distributed under the Creative Commons Attribution License, which permits unrestricted use, distribution, and reproduction in any medium, provided the original work is properly cited.

With the continuous improvement of the planning system for urban subway construction, shield tunnels are being more frequently constructed, and thus, the floating problem of shield tunnels in construction has been paid increasingly more attention. In view of this, in this paper, with the combination of numerical simulation and theoretical analysis, the problem of floating segments compressing the overburden in the deep shield tunnel is discussed. The influential factors of the pressure arch effect are analysed using numerical simulation, the compressive displacement of soil in the plastic zone is investigated in a focused manner based on the pressure arch effect, and the problem of floating segments that the Mindlin solution is applied to under the actions of distributed force and concentrated force is solved. The results show the following: (1) the displacement of the segment is composed of the shield tail gap, the compressive displacement of the soil, and the translational displacement of the soil; (2) the intensity of the pressure arch effect is interactively influenced by the thickness-diameter ratio and the soil properties; (3) the compressive displacement of the soil mass accounts for a larger proportion of floating segment-induced displacements; and (4) the perturbation influence calculation formula of the surrounding strata and the building structure is obtained based on the Mindlin solution.

\section{Introduction}

In the construction of urban underground rail transit, shield tunnelling is increasingly adopted due to its unique advantages in high construction efficiency, minimal noise and disturbance, high automation, and good stability control of surrounding soils. With continuous exploitation of urban underground space, the increase in the buried depth of shield tunnelling is a problem that is faced frequently by engineers. In this respect, the pressure arch effect is going to exert more remarkable impacts on shield tunnelling.

The pressure arch effect has been discovered and analysed for ages. Terzaghi [1] proposed an explanation of the roof arch and the formation mechanism of the ground arch with the loosened ground zone on account of the tunnel construction. Research in this area has included numerical simulations [2-6], theoretical analyses [6-9], and experimental tests $[10,11]$.
Koseki et al. [12] carried out a series of model tests to research the uplift mechanism of various underground structures and obtained the safety factor of underground model structures. The results showed that the uplift of the structures was accompanied by the lateral deformation of the surrounding subsoil. Zhu et al. [13] analysed how the soil pressure, soil displacement, and contact force between soil particles act on the segments against different shield tail gaps, different buried depths, different diameters, and different surrounding soil in dints using laboratory tests, and the results showed that soil arch effect occurred at the scope of 1 to 2 times the shield diameter above the tunnel. Li [14] proposed the formation conditions and the criteria of the pressure arch of the closed ring form, investigated the laws between the overlying or underlying stratigraphic distributions and the natural critical arching depth, and established the indexation formulas of the critical depth for shallow and deep tunnels based on the critical arching of 
single horizontal surrounding soil. Lee and Rowe [15] carried out a series of centrifugal model tests and numerical simulations and determined the boundaries of the arching zones for single tunnelling. Zhang et al. [16] numerically analysed the soil arch throughout the tunnel excavation with respect to the deformation rule of the surrounding soil and stress redistribution. Kong et al. [4] released a method to identify and quantify the extent of the pressure arch using the inner boundary, outer boundary, and centroid line.

Due to the soil arch, in deep or hard soil layers, the vertical soil pressure acting on the segments is not the selfweight of the overburden but a much smaller pressure, as evidenced by a series of field measurements. Segments are covered by groundwater, grout, and slurry and then subjected to the buoyant force. In case the buoyant force is higher than the sum of the self-weight of segments and the overburden, segments will float upward locally. According to the shield tunnelling monitoring data from Shanghai, Guangzhou, Beijing, and other places, the problem of floating segments has become common in shield tunnelling construction. The maximum floating values reached $100 \mathrm{~mm}$ and $150 \mathrm{~mm}$ in the Dalian Road Tunnel and the Xiangyin Road Tunnel, respectively, during their construction. In the Sheng-Tian section in line 3 of the Nanjing Metro, the depth of the shield tunnel was $28 \mathrm{~m}$ on average, the EPBM (Earth Pressure Balance Machine) with a diameter of $6.4 \mathrm{~m}$ was adopted, and the maximum floating value in the construction process reached $76 \mathrm{~mm}$. In line 3 of the Xi'an Metro, floating segments occurred while segments moved out from the shield tail and the maximum value reached $100 \mathrm{~mm}$.

A substantial number of studies have investigated floating segment-induced engineering problems such as the large deformation of the tunnel, the failure of the waterproof layer, and the deviation of the tunnel axis. Ye et al. [17-19] carried out a further study on the causes and effects of floating segments, established the local and longitudinal overall antifloating calculation model, and, moreover, discussed the influence of the joint effect at the segment rings on floating segments. Huang et al. [20] proposed a full-scale model of the horizontal lining structure with the entire ring staggered to conduct a test for the floating problem, thereby determining the value of the stiffness reduction coefficient and the resistance of the bolts of the segment ring. Wei et al. [21] analysed the complex force condition of the segment ring in the floating state and proposed the mechanical model and calculation formula. Ye et al. [22] adopted ABAQUS to build the floating segments numerical model in the construction period considering the fault and opening of the segment ring, and based on the model, the floating value was determined. Dong et al. [23] took the measured data and force analysis as the initial step in studying the phenomenon of floating segments on Nanjing Metro line 3 and investigated the timing of floating segments and measures to resist floating. Chen et al. [5] investigated the impacts of shield-driving parameters including the gradient of the grout pressure, jacking force, and pretightening force of the longitudinal bolts on the uplift behaviour.

\section{Analysis of Floating Segment Perturbation}

With respect to the causes of floating segments, Ye et al. [19] summarized them into six aspects. In the analysis of the mentioned aspects, according to different research angles, they can be divided into two groups, force analysis and displacement analysis. The former took the segment as the research object and analysed its stresses to explain the cause of the motion. Meanwhile, the latter studied the segment and surrounding soil as a whole to explore the movement. So far, existing research is mostly focused on the force analysis, and there has been less research on displacement analysis. In this paper, the influence of floating segments will be examined by means of displacement analysis.

2.1. Theoretical Analysis. During the shield tunnelling process, the segments separate themselves from the shield tail, after which the shield tail gap is formed around segments, which is relatively common in the case of favourable surrounding soil conditions. When the grout is injected into the strata, segments generally lie in the centre of the grout and are covered uniformly. When the surrounding soil is relatively weak, the soil above the segments moves sharply and largely, competing with the grout for the space that belongs to the shield tail gap, which contributes to the most disadvantageous force form of segments, as shown in Figure 1.

The shield tail gap occurs in the shield tunnel throughout the whole construction. During excavation, due to the overexcavation of the cutterhead, the clearance is formed between the cutterhead and the shield shell, and the surrounding soil fills in along the direction of the shield shell to eliminate the gap. In the above process, the stress redistribution occurs in the overburden, thus developing the plastic zone. After the segment moves out from the shield tail, the gap enlarges and the existing loose body moves farther, thus resulting in the expansion of the plastic zone. With respect to the microscopic expression, due to the generation of the free face, the soil particles change from compression to tension and plastic deformation occurs. In the process of deformation, the constraining force between particles is weakened, the gap enlarges continuously, and the resulting soil becomes loose over time. Meanwhile, the grout is injected into the strata and fills in the adjacent gap to form the soil-grout induration. At this point, the soil in the plastic zone forms an annular body centring on the segment, which is gradually denser from the inside to the outside. The internal soil close to segments is unstable soil-grout induration, and the soil near the margin of the plastic zone is basically consistent with the properties of the undisturbed soil. If the surrounding soil with the same property is partitioned, the soils within the plastic zone can be regarded as a soil structure composed of several annular bodies, as shown in Figure 2.

When the tunnel is relatively deep, the surrounding soil generates the pressure arch effect, which has a significant effect on the floating of segments. On the one hand, the presence of the pressure arch can reduce the gravity of the 


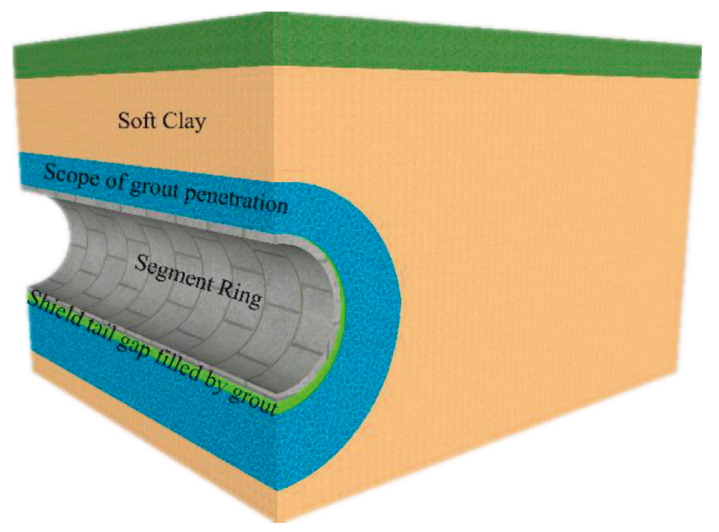

Figure 1: The most disadvantageous form of shield tail gap.

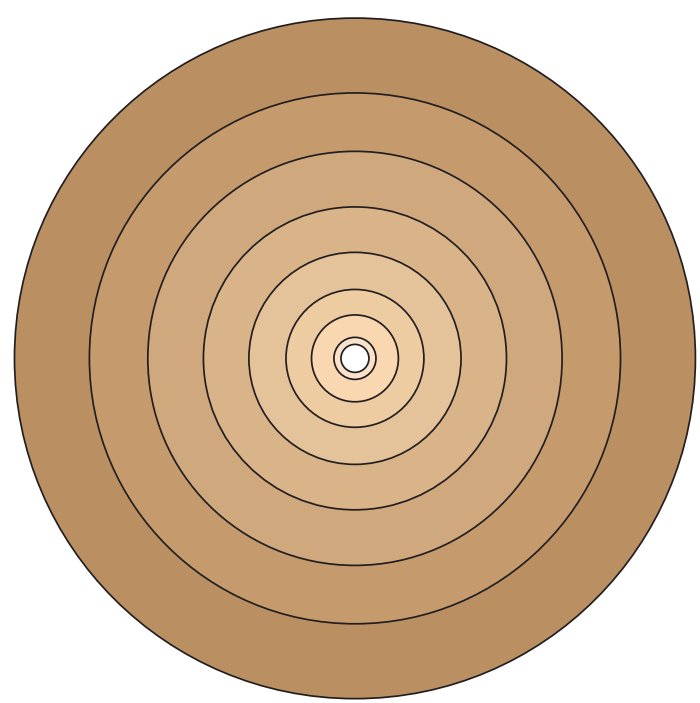

Figure 2: Soil stratification in plastic zone.

overlying soil acting on the segment, and the stronger the pressure arch effect is, the more obvious this effect. On the other hand, when the pressure arch effect is strong, it often means that the compactness of the soil is higher, the ability of the segment to compress soil is weaker, and the segment further promotes the overall movement of the soil in the plastic zone. Therefore, when the geological conditions of surrounding soil are favourable, the floating space of the segment is limited, and no large floating displacement is generated. However, when the surrounding soil conditions are poor, if the segment lifts upward, it will cause greater damage. The overall variation of the surrounding soil at this time is shown in Figure 3.

When the segment lifts upward and compresses the soil, it is first contacted with the lower layer soil above segment and compresses it, the soil particles are squeezed into each other to gradually reduce the interstices between particles, and the intergranular occlusion is tighter. If the segment is subjected to force from the lower layer that is not enough to make it stand still, the segment will squeeze the soil of the lower layer and compress the sublayer soil with the floating posture until the segment reaches the force equilibrium and

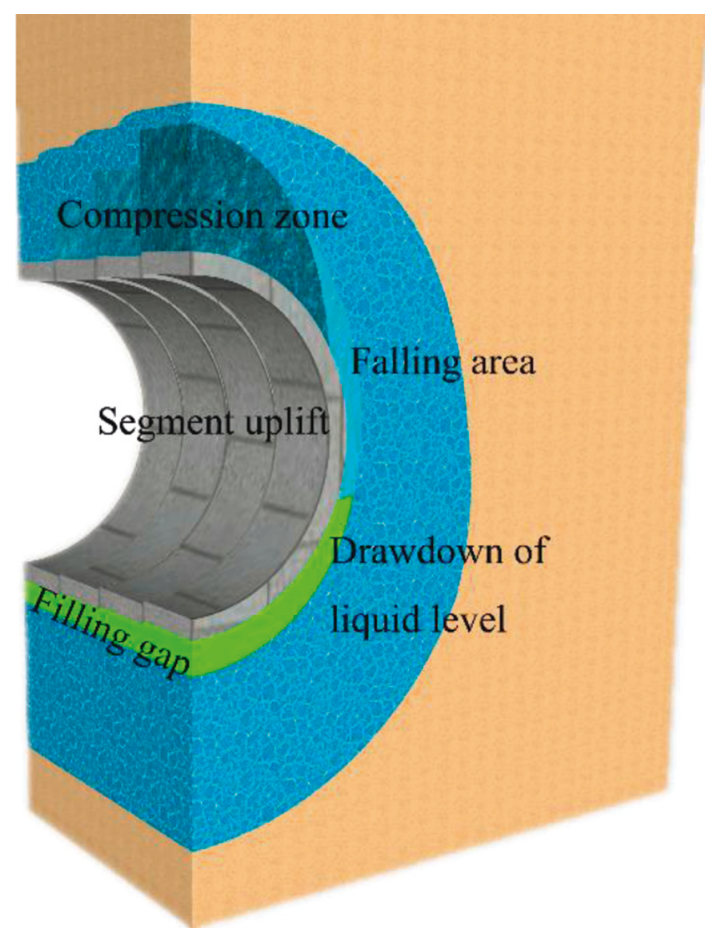

FIGURE 3: Segment floating form.

stops moving. During this process, the segment lifts the plastic body upwards, thus resulting in the compression and consolidation of the soil in the plastic zone. On the other hand, the gap below the segment left by the floating segment is quickly filled back by slurry, which leads to the void on the side of the segment induced by the drawdown of the liquid level on both sides of the segment, and the void is eventually filled by the soil being crushed in the upper part, as shown in Figure 3. Due to the slow movement of the segment, it can be considered that when the segment reaches the force equilibrium, the floating motion is also terminated, and the compression displacement and the translational displacement of the soil in the plastic zone reach their maximums at the same time. In this process, the segment is compressed layer by layer under the action of the buoyant force, and the reverse compression of the soil in the plastic zone provides the displacement space for the upward movement of the segment.

The translational displacement equals zero if there has no floating occurred (Figure 4(a)). Assuming that the soil in the plastic zone is a rigid body, as shown in Figure 4(b), the soil in the plastic zone is subject to the upward buoyant force and moves upwards. From the macroscopic angle, the sum of the vertical translational displacement in the soil belonging to the part of the dark colour and the shield tail gap is the total displacement of the floating segment; however, soil is not rigid, as shown in Figure 4(c). With the action of the upward buoyant force, the compression of the soil inevitably occurs and the translational displacement is small relative to rigid body assumption. The "disappearance" of the displacement results from the compression of the soils. Therefore, the research of the compression displacement is of great significance. On the other hand, the translational 


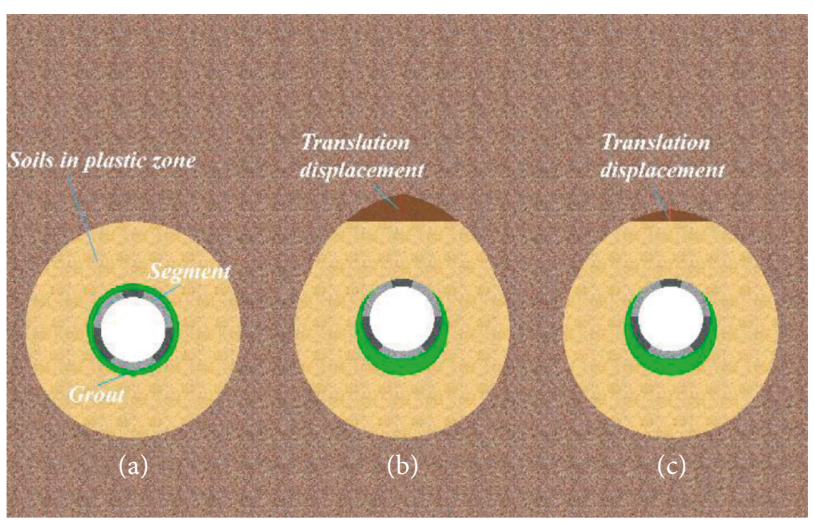

FIGURE 4: Displacement variation diagram of soil in plastic zone. (a) No floating. (b) Floating (rigid body). (c) Floating (nonrigid body).

displacement changes are due to the change in the compression displacement of soils.

Consequently, when the segments and surrounding soil are regarded as a whole in the research, it can be considered that the displacement of the segment uplift is mainly constituted by three parts in space: the shield tail gap in response to the excavation, the contraction displacement of the soil in the plastic zone induced by the pressure on the segment, and the gross translational displacement of soil in the plastic zone.

\section{Numerical Analysis}

Based on the above analysis, the numerical analysis is conducted in this paper to further study the compressive effect of overburden in a deep shield tunnel. The numerical analysis is mainly divided into three parts. First, the available dividing layers in the plastic zone are analysed to obtain reasonable numbers of layers in the plastic zone, which is convenient for the follow-up numerical calculation without impacting the numerical effect. Next, based on the arch effect of the overburden, the compressive displacement of soil in the plastic zone influencing the floating segment is researched specifically to investigate the magnitude of the effect.

\subsection{Relevant Assumption}

3.1.1. Figuration Assumption of the Plastic Zone. In the displacement calculation of points around the tunnel, the lateral pressure coefficient $\lambda$ is different, and thus, the displacement values and distributions are different. The tunnel profile is reduced uniformly as $\lambda$ is equal to 1 . Consequently, for the sake of convenient analysis, it is assumed that $\lambda$ is equal to 1 in this paper.

During the mechanized tunnelling process, due to the gap between the outer diameter of the cutterhead and the outer diameter of the shield shell, the stress redistribution of the surrounding soil occurs until the grout fills into the gap. At that moment, because of the grout, the configuration of the plastic zone changes partly. Nevertheless, for the convenience of modelling, it is assumed that the configuration of the plastic zone is a circular ring.

3.1.2. Assumption of Soil Properties in the Plastic Zone. When $\lambda$ is equal to 1 , the configuration of the plastic zone in the deep shield tunnel is a circle. Under the action of hydrostatic pressure, the Lamy solution of the stress field around the shield tunnel is shown as follows:

$$
\sigma_{r}=\sigma_{0}\left(1-\frac{a^{2}}{r^{2}}\right)
$$

where $\sigma_{r}$ is the radial stress at any point of the surrounding soil, $\sigma_{0}$ is the initial stress of the rock mass, $a$ is the radius of the circular tunnel, and $r$ is the distance from any point to the tunnel centre.

From the Lamy solution of the stress field, there is a negative correlation between the radial stress at any point, $\sigma_{r}$, and the ratio of the radius of the tunnel to the distance, $a / r$. According to similarity theory, it can be considered that the relevant physical parameters of soil in the plastic zone agree with the Lamy solution, i.e., the change in the density, $\rho$, is similar to that in the radial stress.

\subsubsection{Assumption regarding the Arch Conditions.}

Generally, when considering the construction load and the changes after completion, when calculating the relaxed soil pressure and loose height, a lower limit value of the soil pressure must be set and the equivalent soil pressure under the overburden with the height of $2 D$, where $D$ denotes the diameter of the tunnel, is adopted customarily.

The calculation of relaxation soil pressure adopts the Terzaghi [1] formulas.

$$
\begin{aligned}
h_{0}= & \frac{B_{1}\left(1-\left(c / B_{1} \gamma\right)\right)}{K_{0} \tan \phi}\left(1-e^{-K_{0} \tan \phi \cdot\left(H / B_{1}\right)}\right) \\
& +\frac{P_{0}}{\gamma} e^{-K_{0} \tan \phi \cdot\left(H / B_{1}\right)}, \\
\sigma_{\mathrm{v}}= & \frac{B_{1}\left(\gamma-\left(c / B_{1}\right)\right)}{K_{0} \tan \phi}\left(1-e^{-K_{0} \tan \phi \cdot\left(H / B_{1}\right)}\right) \\
& +P_{0} e^{-K_{0} \tan \phi \cdot\left(H / B_{1}\right)}, \\
B_{1}= & R_{0} \cot \left(\frac{\pi / 4+\varphi / 2}{2}\right),
\end{aligned}
$$

where $h_{0}$ is the loose height of the soil, $\sigma_{\mathrm{v}}$ is the Terzaghi vertical relaxation pressure, $B_{1}$ is the width of the loose zone, $K_{0}$ is the ratio of the horizontal soil pressure to the vertical soil pressure ( 1 is generally taken), $\varphi$ is the friction angle, $c$ is the cohesion, $\gamma$ is the unit weight of the soil, and $P_{0}$ is the overburden.

In process of establishing the model, the radius of the plastic zone $r_{0}$ is based on $h_{0}$, the loose height of the soil. In case 1 , the loose height, $h_{0}$, is less than two times the outer diameter of the tunnel, and the radius of the plastic zone is $5 D / 2$ (here, $D$ denotes the outer diameter of the tunnel). In 
case 2 , the loose weight is larger than $2 D$, and the radius of the plastic zone is $h_{0}+D / 2$. The radius equation can be expressed as follows:

$$
r_{0}= \begin{cases}\frac{5 D}{2}, & h_{0} \leq 2 D \\ h_{0}+\frac{D}{2}, & h_{0}>2 D\end{cases}
$$

Here, $r_{0}$ is the radius of the plastic zone in the model, i.e., the distance between the outer boundary of the plastic zone and the centre of the tunnel, and $D$ represents the outer diameter of the segment.

3.2. Analysis of the Number of Critical Layers in the Plastic Zone. In the plastic zone with a uniform soil layer, the properties of the soil change continuously from the segment to the outer boundary of the plastic zone. In the establishment process, in order to simulate the variation in an efficient manner, this paper adopts the limit to disperse it into the continuous layered zones. The thickness and soil parameters of each layer in the plastic zone are based on the graphics of the Lamy solution, as shown in Figure 5. When the layers in the plastic zone continuously increase and the result of the model remains unchanged, the number of layers can be considered as the critical layer number, which is convenient to the model calculation and does not interfere with the result.

The parameters for the simulation model include that the diameter of the shield machine is $6.26 \mathrm{~m}$, the outer diameter of the segment is $6 \mathrm{~m}$, the inner diameter of the segment is $5.4 \mathrm{~m}$, and the width is $1.5 \mathrm{~m}$. The C30 reinforced concrete with the width of $0.3 \mathrm{~m}$ is assigned to the segment. Table 1 shows the soil parameters employed in the 3D FE model. In this part, a total of 10 different numbers of critical layers listing $0,1,2,3,4,5,6,7,8$, and 9 are analysed.

For the convenience of model establishment, the average value of each layer is adopted as the soil parameter of the entire layer. In the beginning, the opposite force balancing the gravity is applied in the layers of the calculation region to simulate the initial crustal stress field. After the tunnel is excavated, the surrounding soil leaves the support of the original soil, resulting in the occurrence of relaxed deformation along the direction of the free face and the generation of the plastic zone. When the segment is out of the shield tail and subjected to static buoyancy and dynamic buoyancy, it floats upward and squeezes the soil layers in the plastic zone until a new balance appears, as shown in Figure 6.

The numerical simulation results show that with the gradual increase of the plastic zone layers, the properties of the soil in each layer gradually become continuous and the floating displacement and compressive displacement of the segments (the difference between the floating displacement of the segment and the translational displacement of the soil) increase significantly, of which the changes are approximately linear. The value of floating displacements and vertical pressures at tunnel crown achieved the maximum

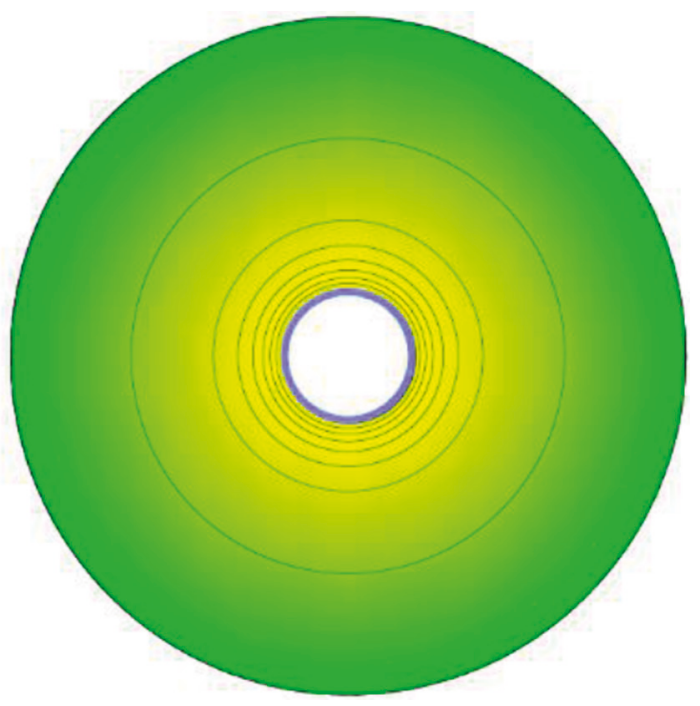

Figure 5: Eight layers in plastic area.

TABle 1: Parameters of materials.

\begin{tabular}{lccccc}
\hline Material & $\begin{array}{c}\text { Unit } \\
\text { weight } \\
\left(\mathrm{kN} / \mathrm{m}^{3}\right)\end{array}$ & $\begin{array}{c}\text { Elastic } \\
\text { modulus } \\
(\mathrm{MPa})\end{array}$ & $\begin{array}{c}\text { Poisson's } \\
\text { ratio }\end{array}$ & $\begin{array}{c}\text { Cohesion } \\
(\mathrm{kPa})\end{array}$ & $\begin{array}{c}\text { Friction } \\
\text { angle }\left(^{\circ}\right)\end{array}$ \\
\hline Silt & 18.7 & 10 & 0.38 & 12 & 20 \\
Segment & 25 & $3.45 \times 10^{4}$ & 0.18 & & \\
\hline
\end{tabular}

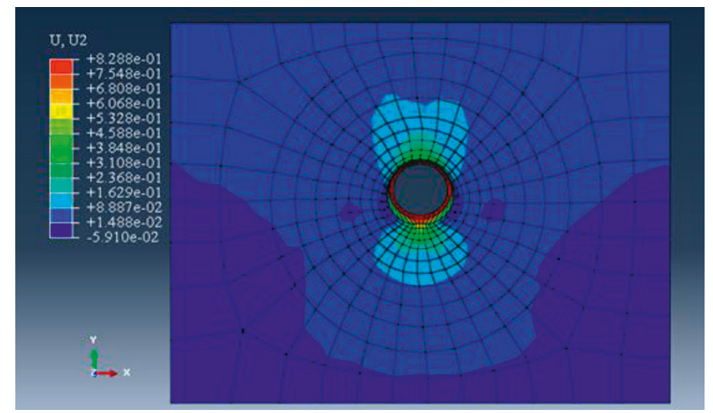

Figure 6: Vertical displacement of eight-layer model.

among all the point on the segment, so we tested the floating displacements and vertical pressures at tunnel crown. When the plastic zone layers reach 8 , two displacements tend to be stable and the vertical stress is almost invariant, as shown in Figure 7. Consequently, it can be believed that when the plastic zone layers reach 8 , the soil properties in the plastic zone are able to represent the actual plastic zone in this numerical simulation. As a result, the layers of the plastic zone are adopted as the critical number of layers to serve as follow-up studies.

3.3. Impact Analysis of Pressure Arch. In existing shield tunnels, the ratio of the depth of the overburden to the outer diameter of the shield, i.e.,the thickness-diameter ratio $(h / D)$, mainly distributes among $0.5 \sim 10$. As a consequence, the shield tunnel studied in this paper is in the section 


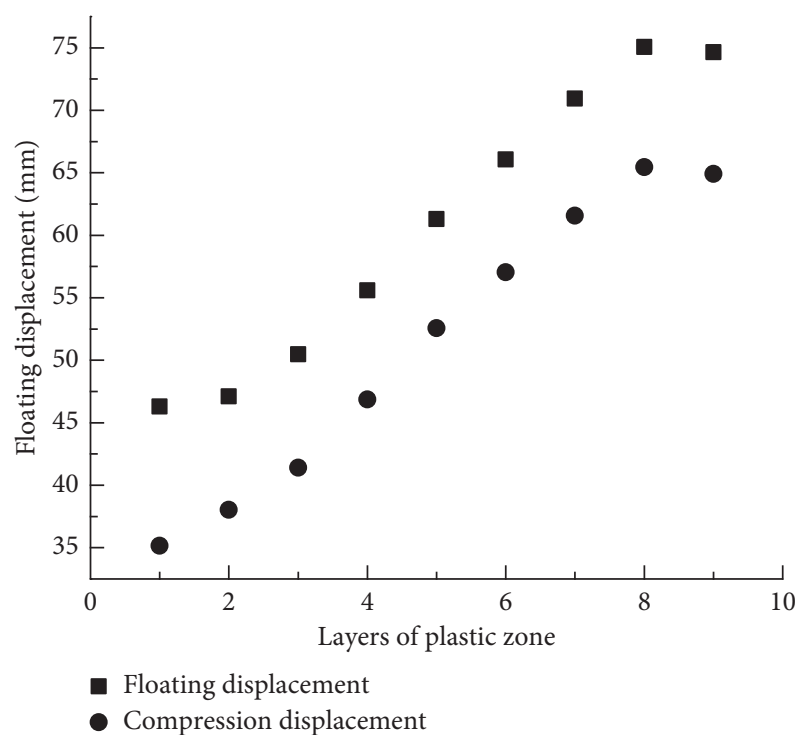

(a)

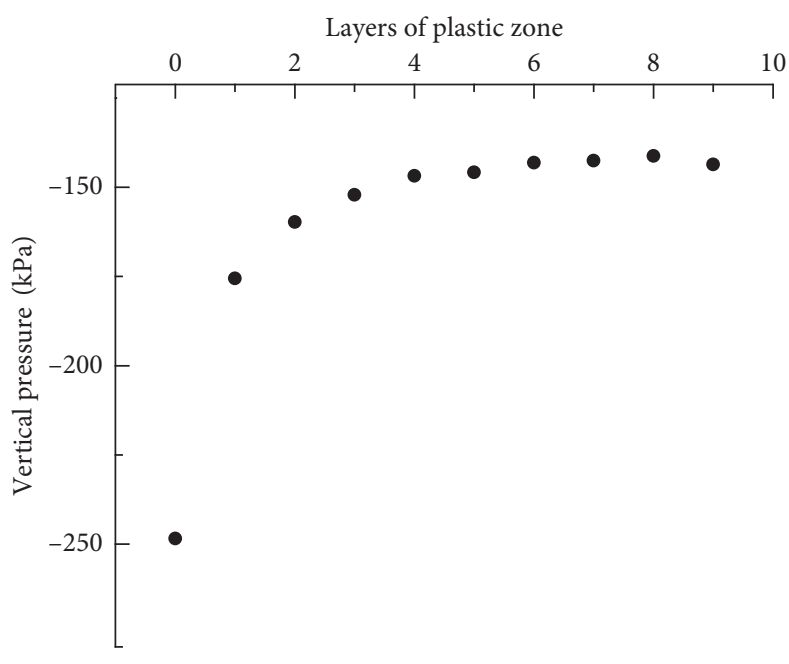

(b)

FIgURE 7: Variation of segment displacement and vertical pressure at different layers.

mentioned above. For the sake of the effective generation of the arch effect, ten conditions are chosen with different thickness-diameter ratios including $2.5,3,3.5,4,5,6,7,8,9$, and 10 .

The loose height, relaxation soil pressure, and radius of the plastic zone are derived by equations (2), (3), and (5), respectively, as shown in Table 2 .

The strength of the pressure arch effect is related to various conditions, such as the soil properties and depth. As a consequence, for the purpose of the unified judgement standard under different conditions, this paper introduces the judging factor, $\eta$. It can be expressed by

$$
\eta=\frac{\sigma}{\sigma_{\mathrm{v}}}
$$

Here, $\sigma_{\mathrm{v}}$ is the vertical relaxation soil pressure calculated by Terzaghi and $\sigma$ is the calculation pressure of the model in the same condition.

Among the ten conditions, this paper extracts the vertical pressure under each condition, as shown in Figure 8. The trend in the figure shows that the judging factor $\eta$ decreases with the increase in the thicknessdiameter ratio and gradually stabilizes. When the ratio is relatively small, the judging factor is large, which indicates that in this condition, most of the overburden acts on the tunnel directly, thus resulting in the weakness of the pressure arch effect. When the ratio is large, the judging factor is small and tends to be stable, i.e.,in this condition, the pressure arch effect is relatively large and tends to be stable.

There is a direct correlation between the strength of the arch effect and the soil property. Consequently, this paper adjusts the soil property to investigate the change in the pressure arch effect under the cross-influence of the thickness-diameter ratio and the soil property. The soil properties are shown in Table 3, and the change in the
TABLE 2: Theoretical calculation results at different working conditions.

\begin{tabular}{lcccc}
\hline $\begin{array}{l}\text { Thickness/ } \\
\text { diameter }\end{array}$ & $\begin{array}{c}\text { Depth of } \\
\text { overburden } \\
(\mathrm{m})\end{array}$ & $\begin{array}{c}\text { Height of } \\
\text { loosen } \\
\text { zone }(\mathrm{m})\end{array}$ & $\begin{array}{c}\text { Vertical } \\
\text { relaxation soil } \\
\text { pressure }(\mathrm{Pa})\end{array}$ & $\begin{array}{c}\text { Radius of } \\
\text { plastic } \\
\text { zone }(\mathrm{m})\end{array}$ \\
\hline 2.5 & 15 & 9.7 & 181073 & 15 \\
3 & 18 & 10.7 & 200868 & 15 \\
3.5 & 21 & 11.6 & 217247 & 15 \\
4 & 24 & 12.3 & 230798 & 15.3 \\
5 & 30 & 13.4 & 251287 & 16.4 \\
6 & 36 & 14.2 & 265314 & 17.2 \\
7 & 42 & 14.7 & 274916 & 17.7 \\
8 & 48 & 15.1 & 281490 & 18.1 \\
9 & 54 & 15.3 & 285990 & 18.3 \\
10 & 60 & 15.4 & 289071 & 18.4 \\
\hline
\end{tabular}

vertical pressure judgement factor in the case of a small ratio and a large ratio is shown in Figures 9 and 10, respectively.

From Figures 9 and 10, under a small thicknessdiameter ratio, the change laws of the judgement factor are the same for the different soil properties, and for the judgement factor, the thickness-diameter ratio accounts for a larger proportion. Currently, the arch effect inside the surrounding soil is weak. With the increase in the thickness-diameter ratio, the judgement factor decreases, the pressure arch effect increases gradually, the compactness of the soil increases, and the floating displacement decreases gradually. Under the large thickness-diameter ratio, the relationship between the judgement factor and the thickness-diameter ratio is weak, but it is strong with the soil property. Currently, a strong pressure arch effect exists in all three types of soils. The more favourable the soil properties are, the smaller the judgement, the stronger the pressure arch effect, the smaller the compression space for the soil, and the smaller the floating displacement of the segments. In addition, it can be seen from Figure 11 that the 


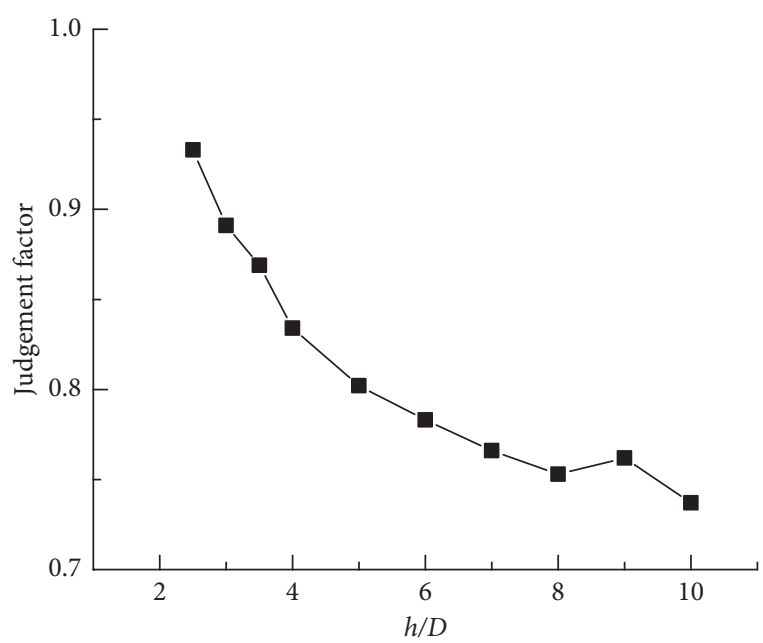

Figure 8: Variation of judgement factor.

TABle 3: Basic properties of the soil.

\begin{tabular}{lccccc}
\hline Material & $\begin{array}{c}\text { Unit } \\
\text { weight } \\
\left(\mathrm{kN} / \mathrm{m}^{3}\right)\end{array}$ & $\begin{array}{c}\text { Elastic } \\
\text { modulus } \\
(\mathrm{MPa})\end{array}$ & $\begin{array}{c}\text { Poisson's } \\
\text { ratio }\end{array}$ & $\begin{array}{c}\text { Cohesion } \\
(\mathrm{kPa})\end{array}$ & $\begin{array}{c}\text { Friction } \\
\text { angle }\end{array}$ \\
\hline $\begin{array}{l}\text { Plastic } \\
\text { clay }\end{array}$ & 20 & 20 & 0.32 & 30 & 14 \\
$\begin{array}{l}\text { Hard } \\
\text { plastic } \\
\text { clay }\end{array}$ & 25 & 32 & 0.29 & 31 & 15 \\
Silt & 18.7 & 10 & 0.38 & 12 & 20 \\
\hline
\end{tabular}

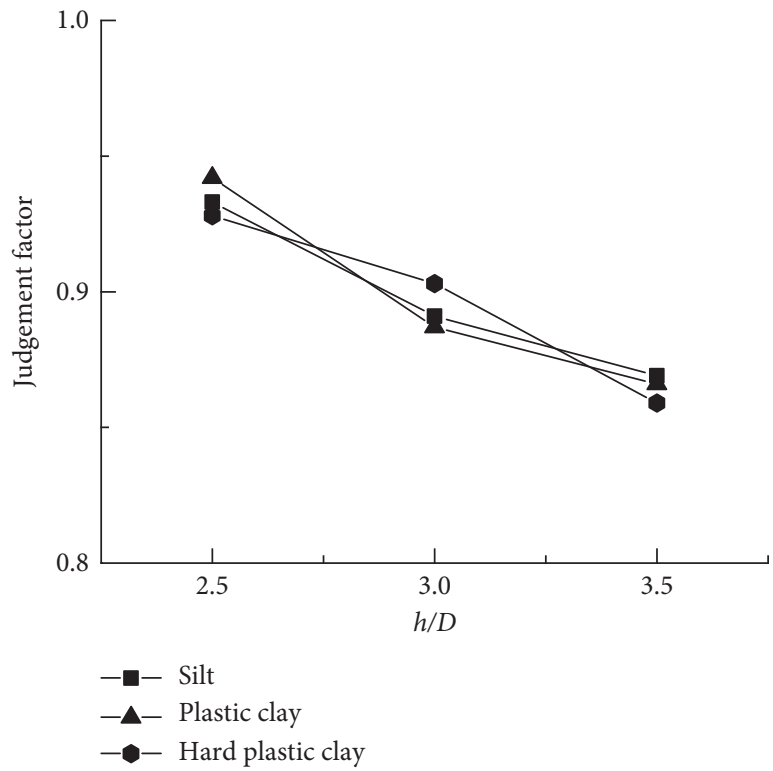

FIgURE 9: Variation of judgement factor at small ratio.

more favourable the soil properties are, the smaller the slope of the relationship between the floating displacement of the segment and the thickness-diameter ratio, i.e.,the stable condition can be achieved under a relatively small thickness-diameter ratio.

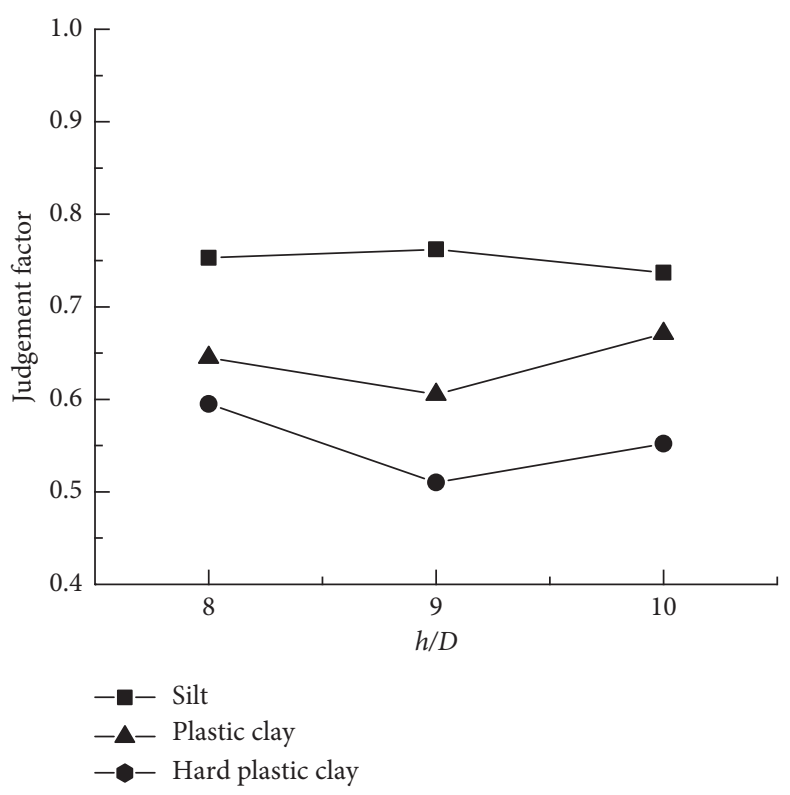

Figure 10: Variation of soil judgement factor at large ratio.

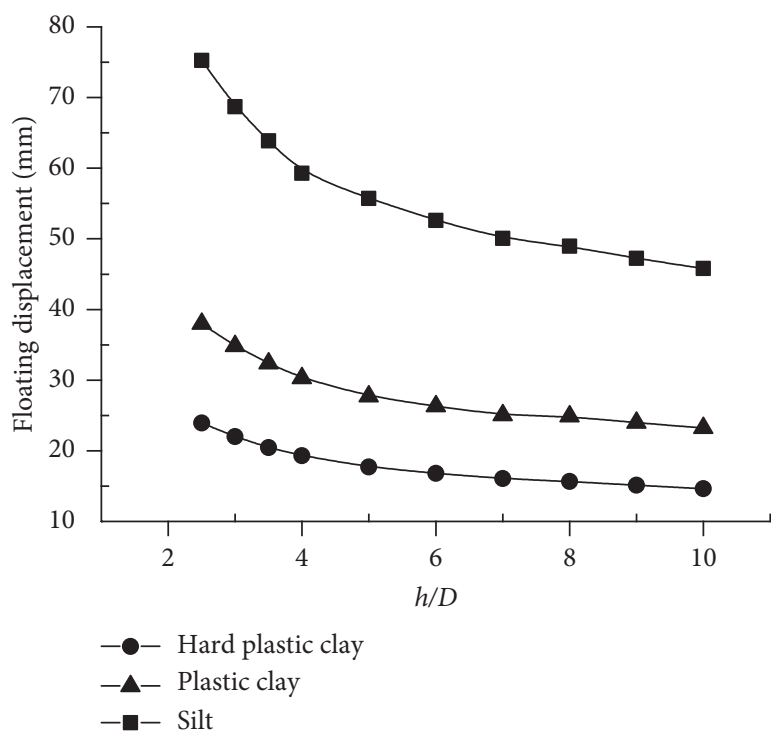

FIGURE 11: Variation of segment displacement at different geological conditions.

3.4. Analysis of the Soil Compactness Effect. Based on the above analysis, the floating displacement of the segment under the condition of silt soil is analysed. The test point of compression displacements is tunnel crown. Figures 12 and 13 show the variation in the floating displacement of the segment and the compression displacement of soil. It can be seen from the figures that when the thicknessdiameter ratio is small, the pressure arch effect is weak, and the displacement of the segment is relatively large. At this time, the compactness of the soil is relatively low, and the compression effect of the floating segments on the plastic zone is more obvious. Soil particles are gradually occluded and compacted under compression, which shows that the compression displacement of the soil is larger at the 


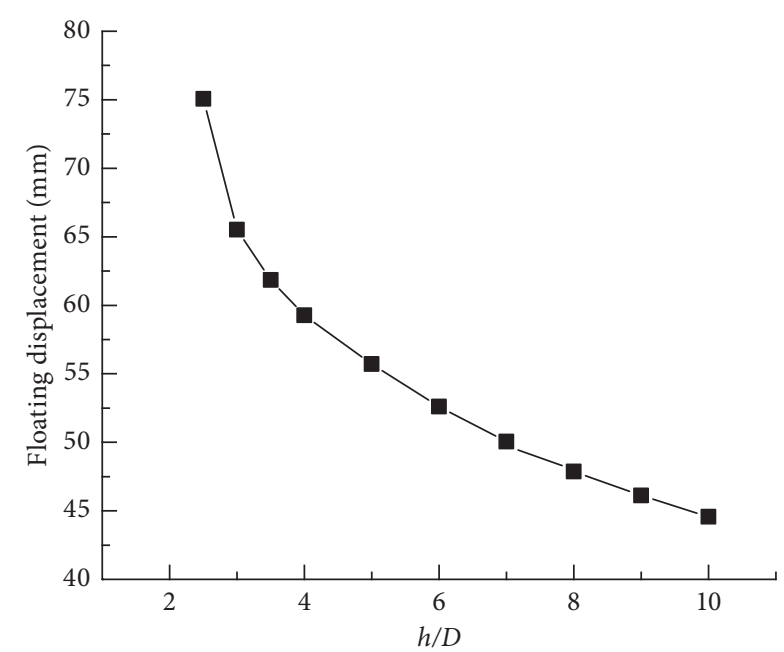

FIGURE 12: Variation of segment floating displacement.

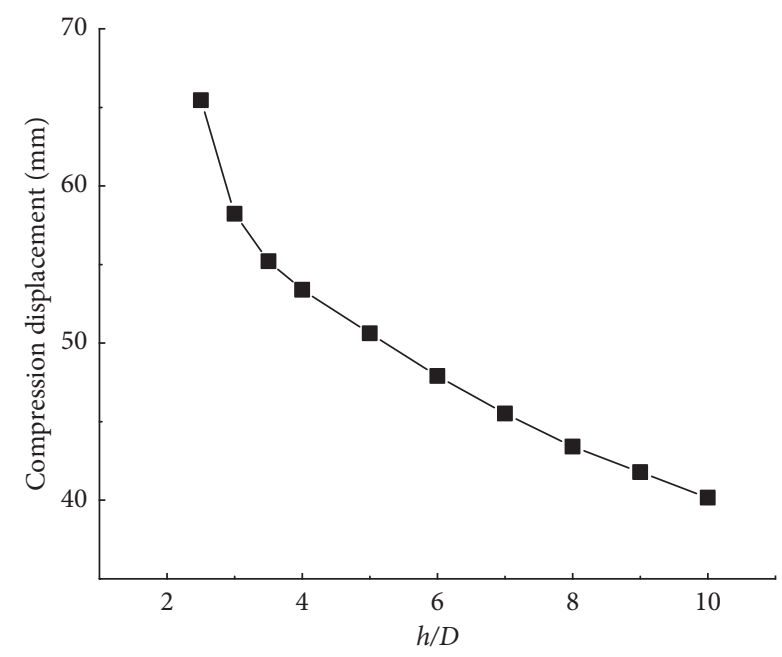

Figure 13: Variation of soil compression displacement.

small thickness-diameter ratio. As the thickness-diameter ratio increases, the pressure arch effect gradually increases, the soil compactness increases, the segment is not prone to compressing the soil, and the floating displacement of the segment and the compression displacement of the soil gradually decrease and tend to flatten. The variation law shows that the floating displacement of the segment in the shield tunnel does not disappear but only decreases with the increase of the buried depth, and eventually stabilizes.

In the deep soft soil shield tunnel, the displacement of the floating segment is determined by the shield tail gap, the compression displacement of the soil, and the translational displacement of the soil. Figure 14 shows the variation in the ratio of the compression displacement of the soil to the floating displacement of the segment. The graphical trend indicates that among the three factors affecting the floating displacement of the segment, the compression displacement of the soil accounts for the largest proportion, and when the thickness-diameter ratio is relatively large, the proportion of the compressive displacement of the soil has the maximum value. As the thickness-diameter ratio

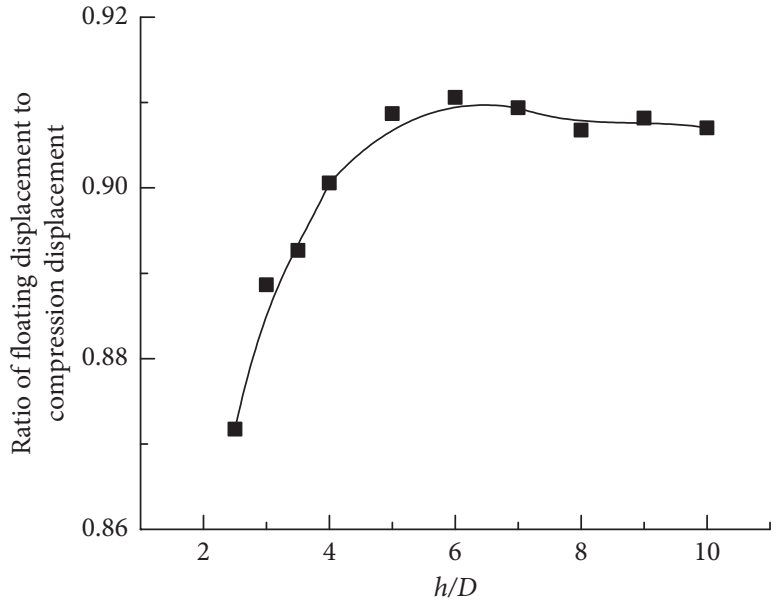

FIgURE 14: Variation of the ratio between soil compression displacement and segment floating displacement.

decreases gradually, the influence of the translational displacement of the soil on the floating displacement of the segment gradually increases.

This phenomenon occurs because when the segment is subjected to the same buoyant force, the vertical relaxation soil pressure is small under the small thickness-diameter ratio, and the stress difference acting on the segment is relatively large. Concurrent with the compressed soil in the plastic zone, it is easier to push the soil up; meanwhile, the proportion of the compression displacement of the soil is smaller than that of the relatively large thickness-diameter ratio. Under the large thickness-diameter ratio, the relaxed soil pressures of each condition are large and similar. Currently, the stress difference in the segment is relatively small, and the segment is prone to compress the soil in the plastic zone. At that moment, the translational displacement of the soil is smaller, and the compression displacement of the soil accounts for a large proportion and tends to be stable with the increase of the thickness-diameter ratio.

\section{Theoretical Analysis of the Surrounding Soil Displacement as Segments Float}

From the analysis mentioned above, the overburden is deformed by the compactness and the reverse compression of the soil in plastic zone provides a displacement space for the floating of the segment ring. This mechanism is similar to that of the subgrade deformation in soil mechanics. The foundation structure transmits loads to the subgrade.

Since the material strength of the upper structure is higher than that of the subgrade and the latter is more easily compressed during the contact squeezing process, the foundation and upper structure are vertically displaced, which is the external representation of the stress change on an object. The upper loads are transmitted to the foundation through the subgrade and diffused in the subgrade. Since the soil is compressible, the subgrade will inevitably deform under additional stress, thereby causing the settlement of the upper structure. 
This phenomenon is similar to the phenomenon of the uplift of the deep shield tunnel segments. When a segment commences floating, it moves inside the grout filled in the shield tail gap at the beginning. If the antibuoyancy provided by shear forces of bolts and the friction between segments is sufficient, at this time, the segment stops moving. If not, the segment will continue floating and start to contact and squeeze the soil in the plastic zone. In this process, the interaction forces between the soil in the plastic zone and the uplifting segments increase until the segments stop floating upward. In the deep shield tunnel, since the distance between the segments and ground surface is long, it is hard for the disturbance effect of the overburden induced by floating segment to transmit to the ground surface. Furthermore, the floating displacement is generally small, and as a consequence, this progress is similar to that of the compression of the building foundation to the subgrade. Based on this analysis, the method for the subgrade settlement calculation in soil mechanics is applied in this paper to solve and analyse the effect produced by the uplifting segments.

4.1. Solution to Floating Segments. The research object of the Mindlin [24] solution is the concentrated force acting on the inside of the soil. However, in a practical project, the load does not appear in the form of a concentrated force. Therefore, in the application process of the Mindlin solution, numerous scholars transformed the surface force to the concentrated force in general and applied it.

In the problem of floating segments in a deep shield tunnel, the influence of the floating segment on the soil in the plastic zone can be approximately considered as that of the vertical concentrated force acting on the inside of the soil, which, using the dint of the Mindlin solution, can solve the stress field and displacement field of soil in the plastic zone with the action of the vertical force. Unlike the problem of a building foundation, there is a large probability that a few buildings are located above the shield tunnel in a city. While the distance between the structure and the shield tunnel is on a different scope, and due to the radius of the segment being large, the floating load acting on the segment cannot be simply regarded as the concentrated force. When the building is far away from the segment ring, the depth of the overburden is large. As a consequence, the acting force of the segment on the soil is effectively superimposed, and the building structure can be completely affected by the entire distributional force. When the building is close to the segment ring, the influence of the size of the segment needs to be considered. Therefore, this paper solves the problem of floating segments based on the distribution force and concentrated force.

4.1.1. Concentrated Force. When the building structure is relatively far from the segment, the load of the segment on the soil can be approximated as a concentrated force. In this case, the load acting on the inside of soils is represented as follows:

$$
P_{1}=F_{\text {buo }}-G-F_{\text {res }},
$$

where $G$ is the gravity of the segment ring, i.e., $G=\rho$ $V=\rho \cdot(4 \pi / 3)\left(r_{1}^{3}-r_{2}^{3}\right) ; r_{1}$ and $r_{2}$ are the outer diameter and inner diameter, respectively; $F_{\text {res }}$ is the shear force of the bolt and the friction of the segment; and $F_{\text {buo }}$ represents the total action force acting on the segment, which mainly includes the force of the grout on the segment and the force of the jack on the segment. In equation (7), except for gravity, the other two forces cannot be measured easily. However, in consideration of the practical construction process, the floating displacement is easily obtained. Therefore, the required force of the same compression displacement induced by the same soil property from the test approximately represents the load acting on the inside of the soil, $P_{1}$.

When solving the stress field and displacement field at the direction $h_{1}$ directly above the segment under the action of the concentrated $P_{1}$ at the buried depth, $h$, the calculation model diagram is shown in Figure 15.

At the moment when the load action depth $c=h$ and the radius $r=0, R_{1}=h_{1}, R_{2}=2 c-h_{1}=2 h-h_{1}, z=c-h_{1}=$ $h-h_{1}$, the stress field and displacement field at that point are as follows:

$$
\begin{aligned}
w_{1}= & \frac{-P_{1}}{4 \pi G(1-\mu)}\left[\frac{1-\mu}{h_{1}}+\frac{2(1-\mu)^{2}}{2 h-h_{1}}+\frac{h\left(h-h_{1}\right)}{\left(2 h-h_{1}\right)^{3}}\right], \\
\sigma_{r 1}= & \sigma_{\theta 1}=\frac{-P_{1}}{8 \pi(1-\mu)}\left[-\frac{(1-2 \mu)}{h_{1}^{2}}+\frac{(1-2 \mu)^{2}}{\left(2 h-h_{1}\right)^{2}}-\frac{6 h^{2}}{\left(2 h-h_{1}\right)^{4}}\right], \\
\sigma_{z 1}= & \frac{-P_{1}}{8 \pi(1-\mu)}\left[\frac{(4-2 \mu)}{h_{1}^{2}}-\frac{(1-2 \mu) h_{1}}{\left(2 h-h_{1}\right)^{3}}-\frac{3(3-4 \mu)\left(h-h_{1}\right)}{\left(2 h-h_{1}\right)^{3}}\right. \\
& \left.-\frac{9 h\left(2 h-3 h_{1}\right)}{\left(2 h-h_{1}\right)^{4}}\right] .
\end{aligned}
$$

4.1.2. Distribution Force. When the position of the building needs to be solved close to the segment, the influence of the size of the segment ring cannot be ignored. Since the segment ring itself is relatively rigid and the buoyant force is comparatively uniform, the compression of the segment ring to the plastic zone can be approximated as a uniform load. In general, the displacement of the segment is usually small and is much smaller than the radius of the segment ring. Therefore, when the segment floats upward, the segment ring in contact with the plastic zone is also much smaller in the lateral direction than the circumference of the segment ring. Therefore, considering the distribution of the uniform load, it is assumed that it is only distributed in the longitudinal direction, as shown in Figure 16. When the uniform load acts on the soil, point A on the axis will produce the maximum displacement. Therefore, in the follow-up research, the stress field and displacement field at point $\mathrm{A}$ are mainly investigated. 


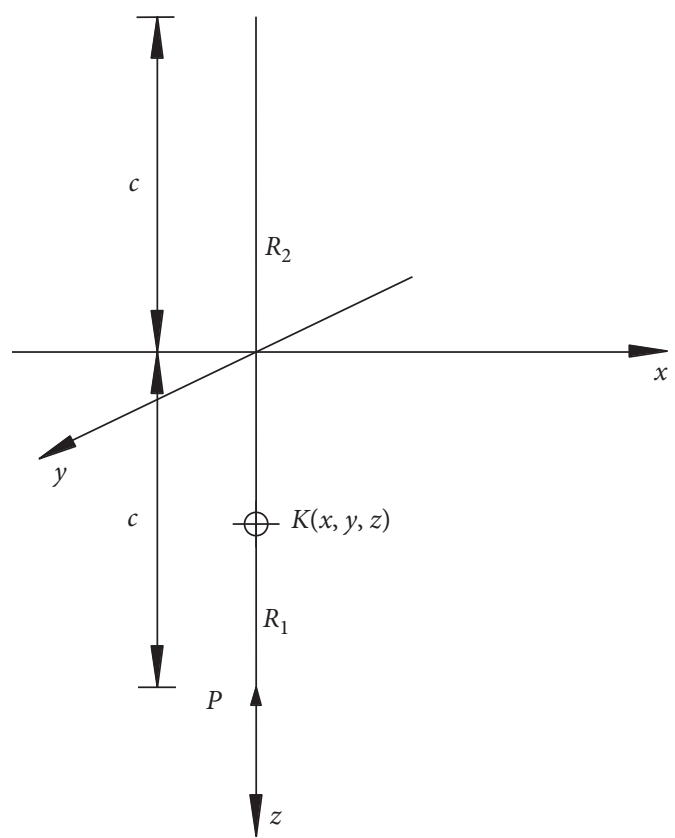

FIGURE 15: Schematic diagram of the calculation model under the condition.

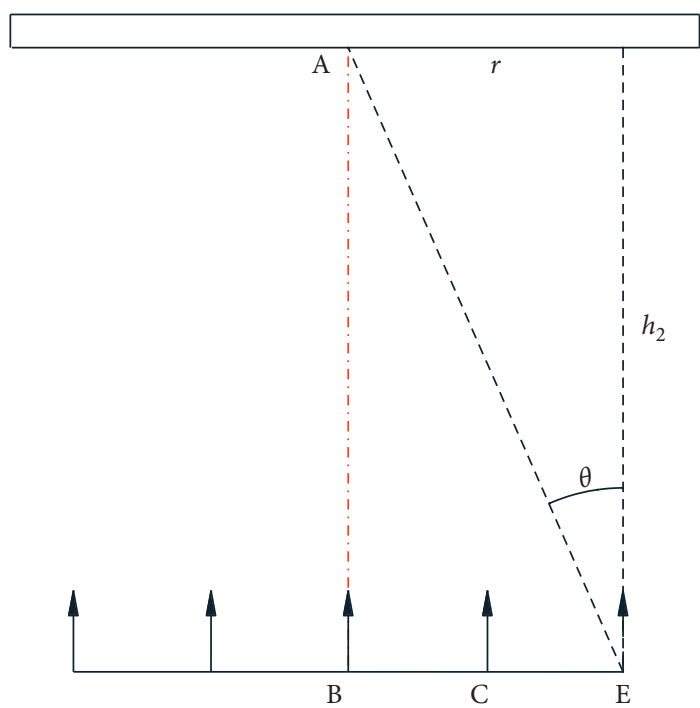

FIGURE 16: Sketch of the effect of uniform load.

When point $A$ is subjected to the acting force from point $\mathrm{B}, \theta$ is the minimum value 0 . When point $\mathrm{A}$ is subjected to the acting force from point $E, \theta$ is the maximum value $\arctan \left(l / 2 h_{2}\right)$. The magnitude of the uniform load is

$$
P_{2}=\frac{P_{1}}{l},
$$

where $l$ is dimensionless and its value is equal to the length of the segment ring, and $P_{1}$ is the load of the entire segment ring applied to the soil.

When solving the stress field and displacement field at the position $h_{2}$ directly above the segment under the action of $P_{2}$, the action depth is $c=0$. We set the radius $R=R_{1}=R_{2}=\left(h_{2}^{2}+r^{2}\right)^{1 / 2}=\left(h_{2} / \cos \theta\right), z=h_{2}, \quad r \in$ $[0,(l / 2)]$, and the vertical displacement of point $\mathrm{A}$ induced by point $\mathrm{C}$ in the segment is as follows:

$$
\begin{aligned}
w_{2} & =\frac{P_{2}}{4 \pi G}\left(2 \frac{1-\mu}{R}+\frac{z^{2}}{R^{3}}\right) \\
& =\frac{P_{1}}{4 \pi G l}\left(2 \frac{1-\mu}{h_{2}} \cos \theta+\frac{h_{2}^{2}}{h_{2}^{3}} \cos ^{3} \theta\right) \\
& =\frac{P_{1}}{4 \pi G l h_{2}}\left[2(1-\mu) \cos \theta+\cos ^{3} \theta\right] .
\end{aligned}
$$

The vertical stress is as follows:

$$
\begin{aligned}
\sigma_{z} & =-\frac{P_{2}}{2 \pi} \frac{3 z^{3}}{R^{5}} \\
& =-\frac{3 P_{1}}{2 \pi l} \frac{h_{2}^{2}}{h_{2}^{5}} \cos ^{5} \theta \\
& =-\frac{3 P_{1}}{2 \pi l h_{2}^{3}} \cos ^{5} \theta .
\end{aligned}
$$

By integrating equation (10), the vertical displacement of the distribution force at point $\mathrm{A}$ is as follows:

$$
\begin{aligned}
W_{2}= & \frac{P_{1}}{4 \pi G l h_{2}} 2 \int_{0}^{\arctan l / 2 h_{2}}\left[2(1-\mu) \cos \theta+\cos ^{3} \theta d \theta\right] \\
= & \frac{P_{1}}{2 \pi G l h_{2}}\left[\int_{0}^{\arctan l / 2 h_{2}} 2(1-\mu) \cos \theta d \theta\right. \\
& \left.+\int_{0}^{\arctan l / 2 h_{2}} \cos ^{3} \theta d \theta\right] \\
= & \frac{P_{1}}{2 \pi G l h_{2}}\left[2(1-\mu) \cdot \frac{l}{2 R_{\mathrm{m}}}+\frac{l}{2 R_{\mathrm{m}}}-\frac{1}{3} \cdot \frac{l^{3}}{8 R_{\mathrm{m}}^{3}}\right] \\
= & \frac{P_{1}}{2 \pi G l h_{2}}\left[(3-2 \mu) \cdot \frac{l}{2 R_{\mathrm{m}}}-\frac{l^{3}}{24 R_{\mathrm{m}}^{3}}\right] .
\end{aligned}
$$

Here, $R_{\mathrm{m}}$ is the maximum of the radius $R$, i.e., $R_{m}=\left(h_{2}^{2}+\left(l^{2} / 4\right)\right)^{1 / 2}$.

By integrating equation (11), the vertical stress of the distribution force at point $\mathrm{A}$ is as follows:

$$
\begin{aligned}
\sigma_{z 2} & =-\frac{3 P_{1}}{2 \pi l h_{2}^{3}} \cos ^{5} \theta \\
& =-\frac{3 P_{1}}{2 \pi l h_{2}^{3}} \int_{0}^{\arctan l / 2 h_{2}} \cos ^{5} \theta d \theta \\
& =-\frac{3 P_{1}}{2 \pi l h_{2}^{3}}\left(\frac{l}{2 R_{\mathrm{m}}}-\frac{2}{3} \cdot \frac{l^{3}}{8 R_{\mathrm{m}}^{3}}+\frac{1}{5} \cdot \frac{l^{5}}{32 R_{\mathrm{m}}^{5}}\right) .
\end{aligned}
$$

In a practical project, since the calculation of the concentrated force is relatively simple, when the distance is far 
and the size of the segment can be ignored, the concentrated force is often used to replace the distribution force and generally its value exists as the maximum limit value of the influence. However, in terms of accuracy, the distribution force is greater than the concentrated force. Therefore, the subsequent part of this section will mainly analyse the distributional force.

4.1.3. Analysis of Examples. The relevant parameters of this part are derived from the geological survey data report of the shield tunnel of the Hang-Hang section of Xi' an Metro Line 4. Since the research object is a deep shield tunnel, the parameter value is the maximum buried depth of the shield tunnel vault. According to the geological survey data, the preconsolidation pressure at this depth is $P_{\mathrm{c}}=419.8 \mathrm{kPa}$, and the compressive modulus of the soil $E_{\mathrm{s}}=30 \mathrm{MPa}$. After several consolidated quick shear tests, the recommended values for the soil material parameters are a cohesion of $c=$ $33.5 \mathrm{kPa}$ and an shear strength angle of $\varphi=24^{\circ}$. According to the China Railway No. 8 (CTE6250) earth pressure balance shield employed in the shield tunnel of Xi' an Metro line 4 , the outer diameter of the cutterhead is $6280 \mathrm{~mm}$, and the outer diameter of both the shield shell of the middle shield and the shield tail is $6240 \mathrm{~mm}$, i.e., $r_{0}=3140 \mathrm{~mm}$ and $r_{b}=3120 \mathrm{~mm}$.

To reduce the difficulty of the research and facilitate the development of the subsequent analysis, it is necessary to utilize the content of the abovementioned geological survey report for the approximate values of some parameters in this section.

Assuming that the homogeneous soil is isotropic, the initial uniform earth pressure $P_{0}$ is approximately equal to the preconsolidation pressure $P_{c}$ of the soil, i.e., $P_{0}=419.8 \mathrm{kPa}$. We take Poisson's ratio of the soil as $\mu=0.3$ and the deformation modulus of the soil within the plastic zone as $E_{0}=E_{\mathrm{s}} \cdot\left(1-\left(2 \mu^{2} / 1-\mu\right)\right)=22.2 \mathrm{MPa}$. The elastic modulus of the soil within the elastic zone is twice the modulus of the deformation, i.e., $E=2 E_{0}=45 \mathrm{MPa}$. The buried depth of the tunnel is $22 \mathrm{~m}$, the elastic modulus $E$ of the soil is $45 \mathrm{MPa}$, and Poisson's ratio $\mu$ is 0.3 , which can obtain the shear modulus of the soil as $G=E / 2(1-\mu)=17.3 \mathrm{MPa}$.

Figure 17 is the disturbance displacement diagram of the upper structure induced by the floating segments under the parameters of this part. The figure reflects the influences of the buoyant force and the structural spacing on the disturbance displacement. Overall, the dark blue region in the figure is more biased towards the structural spacing, thus indicating that the overall effect of the buoyant force on the disturbance displacement is greater than the effect of the structural spacing on the disturbance displacement. Furthermore, as the buoyant force increases, the disturbance displacement exhibits a linearly increasing variation; however, as the structural spacing decreases, the growth rate of the disturbance displacement increases. This characteristic shows that when the structural spacing is small, the influence of the structural spacing on the disturbance displacement is greater than the influence of the buoyant force.

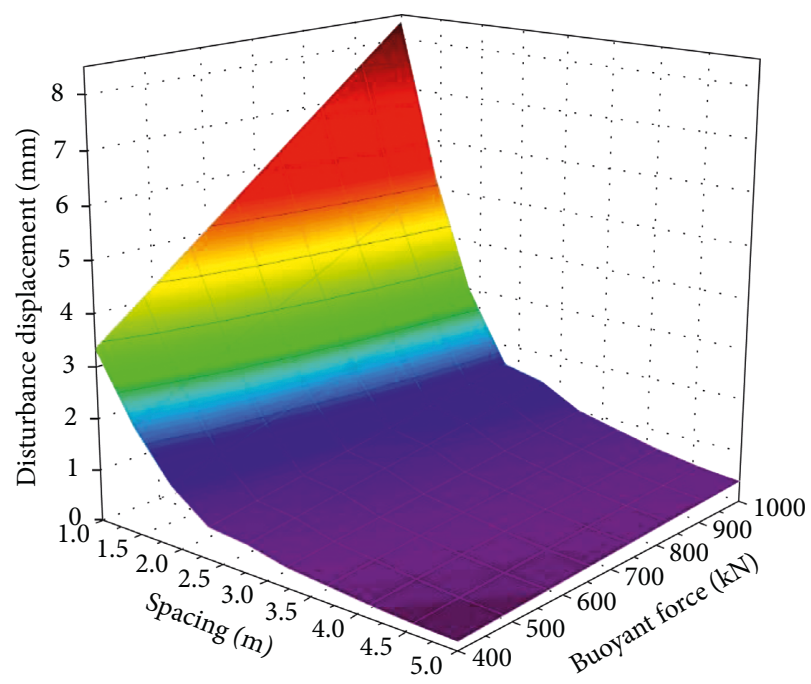

FIGURE 17: Variation of displacement under the action of distributed force.

\section{Conclusions}

In the problem of segment uplift compressing the overburden, this paper investigates the displacement variation during the movement process using the combination of a numerical simulation and theoretical analysis and studies the applicability of the Mindlin solution to the segment uplift problem. Based on the analysis, the following conclusions can be drawn:

(1) The segment uplift is mainly constituted by three parts in space: the shield tail gap in response to the excavation, the contraction displacement of the soil in the plastic zone induced by the squeeze of the segment, and the gross translational displacement of the soil in the plastic zone.

(2) With the increase in the thickness-diameter ratio, the floating displacement of the shield segment has not disappeared but gradually decreases and tends to a stable value, i.e.,whether the shield segment is floating or not has no effect on the tunnel depth, whereas it is related to the construction process of the shield.

(3) When the buried depth of the shield tunnel in the soft soil area is large, due to the influence of the pressure arch effect, the buoyant force acting on the soils in the plastic zone is compressed layer by layer, and the compression displacement of the soil accounts for a large proportion of the floating displacement of the segment.

(4) The pressure arch effect has a significant effect on the size of the floating displacement of the segment. On the one hand, the presence of the pressure arch can reduce the gravity of the soil in the plastic zone acting on the segment, and the stronger the pressure arch effect is, the more obvious this effect. On the other hand, when the pressure arch effect is strong, it often means that the soil compactness is higher, 
and the ability of the segment to compress the soil is weaker.

(5) Based on the theoretical analysis of floating segments, the calculation expression of the disturbance displacement and the stress of the surrounding soil and building structure are obtained using the Mindlin solution. According to the analysis of the example, when the structural spacing is small, the influence of the structural spacing on the disturbance displacement is much greater than the influence of the buoyant force on the disturbance displacement.

\section{Data Availability}

The data used to support the findings of this study are included within the article.

\section{Conflicts of Interest}

The authors declare that there are no conflicts of interest regarding the publication of this paper.

\section{Acknowledgments}

This study was supported by the National Natural Science Foundation for General Project of China (Grant Nos. 51678062 and 51878060).

\section{References}

[1] K. Terzaghi, Rock Defects and Load on Tunnel Supports Rock Tunneling with Steel Supports, Commercial Shearing and Stamping Co., Youngstown, OH, USA, 1946.

[2] S.-R. Wang, C.-L. Li, Y.-G. Wang, and Z.-S. Zou, "Evolution characteristics analysis of pressure-arch in a double-arch tunnel," Tehnicki Vjesnik-Technical Gazette, vol. 23, no. 1, pp. 181-189, 2016.

[3] B. Chevalier, G. Combe, and P. Villard, "Experimental and discrete element modeling studies of the trapdoor problem: influence of the macro-mechanical frictional parameters," Acta Geotechnica, vol. 7, no. 1, pp. 15-39, 2012.

[4] X. X. Kong, Q. S. Liu, Q. B. Zhang, Y. X. Wu, and J. Zhao, “A method to estimate the pressure arch formation above underground excavation in rock mass," Tunnelling and Underground Space Technology, vol. 71, pp. 382-390, 2018.

[5] R.-P. Chen, F.-Y. Meng, Y.-H. Ye, and Y. Liu, "Numerical simulation of the uplift behavior of shield tunnel during construction stage," Soils and Foundations, vol. 58, no. 2, pp. 370-381, 2018.

[6] C.-Y. Chen and G. R. Martin, "Soil-structure interaction for landslide stabilizing piles," Computers and Geotechnics, vol. 29, no. 5, pp. 363-386, 2002.

[7] C. Li, "Developing an analytical method to study vertical stress due to soil arching during tunnel construction," Geotechnical and Geological Engineering, vol. 34, no. 4, pp. 1247-1255, 2016.

[8] X. Han and Y. Xia, "Analytic Solutions of the forces and displacements for multicentre circular arc tunnels," Mathematical Problems in Engineering, vol. 2018, Article ID 8409129, 14 pages, 2018.

[9] X. Han, Y. Xia, X. Wang, and L. Chai, "Complex Variable Solutions for Forces and Displacements of Circular Lined
Tunnels," Mathematical Problems in Engineering, vol. 2018, Article ID 2037845, 12 pages, 2018.

[10] J. Song, Y. Gao, and S. Liu, "Analysis of the effect of groundwater on soil arch in shield tunneling," Arabian Journal of Geosciences, vol. 11, no. 18, 2018.

[11] X.-R. Liu, J. Liu, L.-H. Huang, Z-J. Wang, H.-J. Chen, and Y. Feng, "Model test and pressure arch analysis for excavation of loess double arch tunnel," Journal of Zhejiang University (Engineering Science), vol. 52, no. 6, pp. 1140-1149, 2018.

[12] J. Koseki, O. Matsuo, and Y. Koga, "Uplift behavior of underground structures caused by liquefaction of surrounding soil during earthquake," Soils and Foundations, vol. 37, no. 1, pp. 97-108, 1997.

[13] W. Zhu, X. C. Zhong, and R. Jia, "Simulation on relaxation effect of vertical earth pressure for shield tunnels by particle flow code," Chinese Journal of Geotechnical Engineering, vol. 30, no. 5, pp. 750-754, 2008.

[14] K. Li, Pressure Arch Theory Study of Horizontal Bedded Tunnel Surrounding Rock, Southwest Jiaotong University, Chengdu, China, 2005.

[15] K. M. Lee and R. K. Rowe, "An analysis of three-dimensional ground movements: the Thunder Bay tunnel," Canadian Geotechnical Journal, vol. 28, no. 1, pp. 25-41, 1991.

[16] P. Zhang, D.-C. Lu, X.-L. Du, and C. Ma, "Division method for deep and shallow tunnels," Chinese Journal of Geotechnical Engineering, vol. 35, no. 2, pp. 422-427, 2013.

[17] F. Ye, H. H. Zhu, and W. Q. Ding, "Analysis of anti-upward moving calculation mode of shield tunnel and its adaptability," Journal of Highway and Transportation Research and Development, vol. 26, no. 5, pp. 91-96, 2009.

[18] F. Ye, H. H. Zhu, and W. Q. Ding, "Analysis on antibuoyancy calculation in excavation of big cross-section shield tunnel," Chinese Journal of Underground space and Engineering, vol. 3, no. 5, pp. 49-53, 2007.

[19] F. Ye, H. H. Zhu, and W. Q. Ding, "Longitudinal upward movement analysis of shield tunnel based on elastic foundation beam," China Railway Science, vol. 29, no. 4, pp. 65-69, 2008.

[20] Z. H. Huang, Q. Q. Ji, and J. X. Lin, "Experimental study on the anti-uplift of super- large diameter slurry balance shield tunnel structure," Chinese Journal of Underground Space and Engineering, vol. 6, no. 2, pp. 250-254, 2010.

[21] G. Wei, J. Hong, and X.-J. Wei, "Mechanical analysis of segment floating during shield tunnel construction," Chinese Journal of Rock Mechanics and Engineering, vol. 31, no. 6, pp. 1257-1263, 2012.

[22] J.-N. Ye, Y. Liu, and R.-P. Chen, "Study of the permissible value of upward floating for segment in tunnel construction," Chinese Journal of Rock Mechanics and Engineering, vol. 33, no. 2, pp. 4067-4074, 2014.

[23] S. S. Dong, P. Yang, and C. Jiana, "Analysis of mechanism and controls of segment floating of shield tunnels," Chinese Journal of Underground Space and Engineering, vol. 12, no. 1, pp. 49-54, 2016.

[24] R. D. Mindlin, "Force at a point in the interior of a semiinfinite solid," Physics, vol. 7, no. 5, pp. 195-202, 1936. 


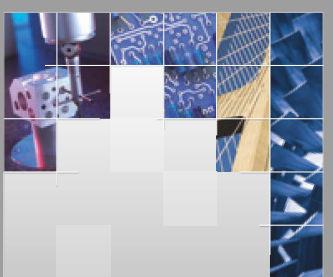

\section{Enfincering}
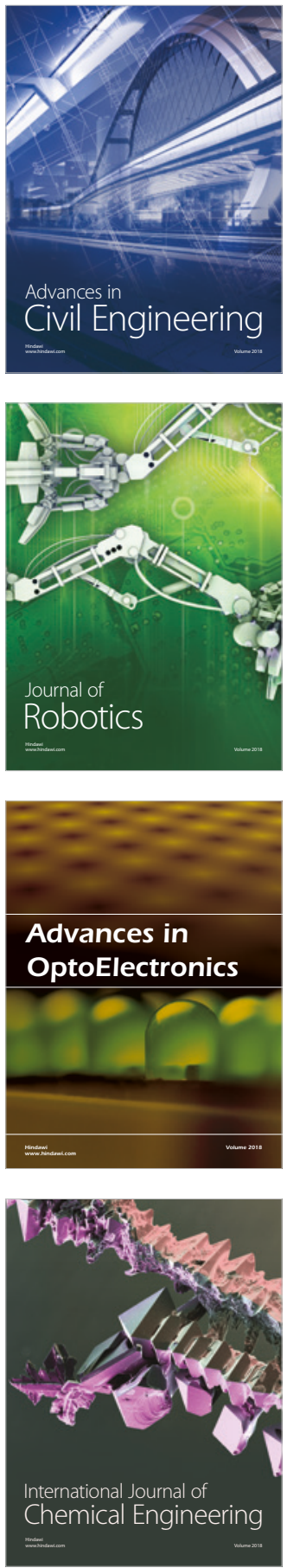

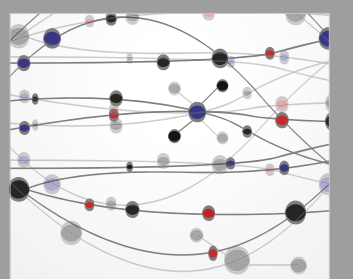

\section{Rotating \\ Machinery}

The Scientific World Journal

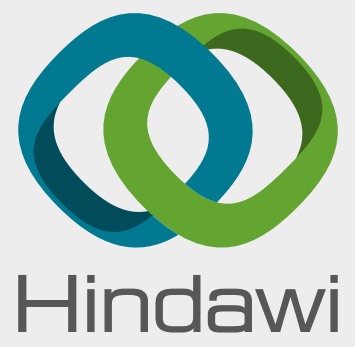

Submit your manuscripts at

www.hindawi.com
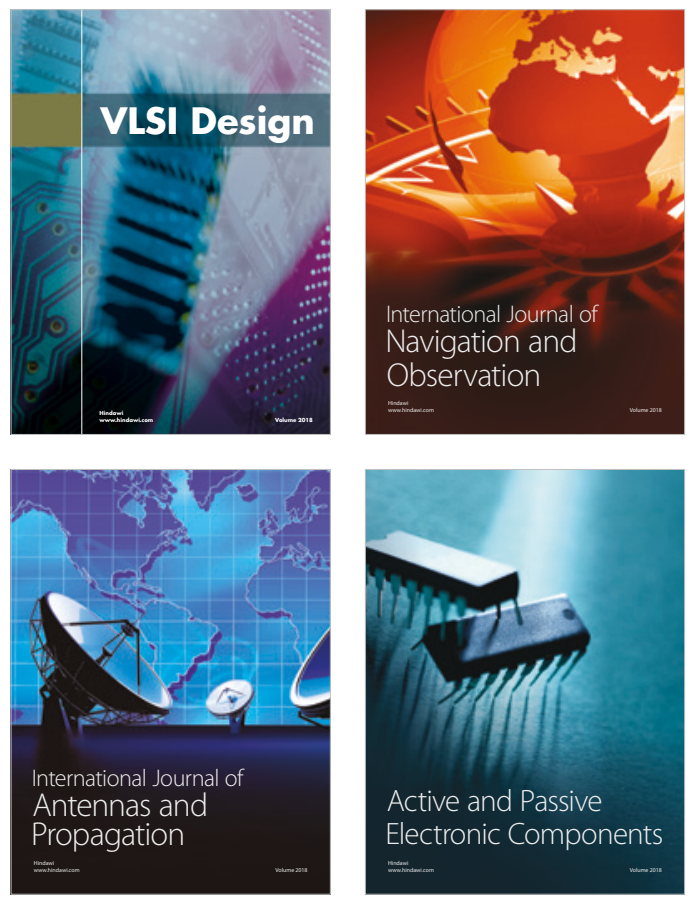
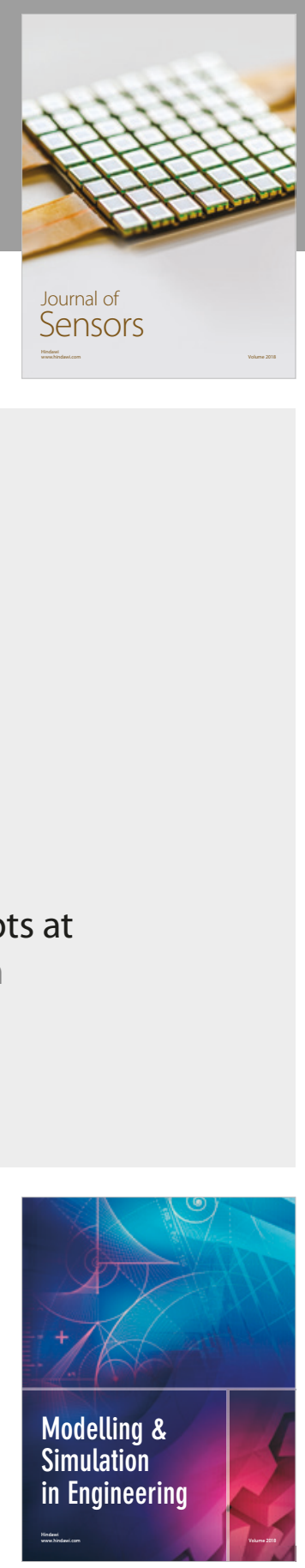

\section{Advances \\ Multimedia}
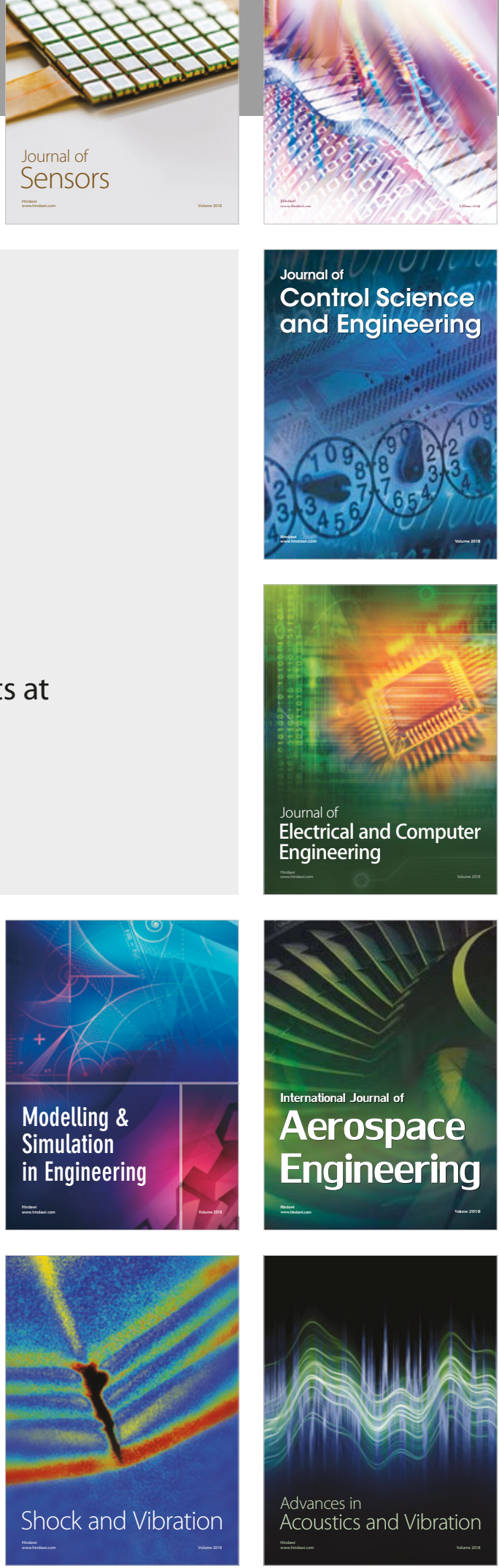